\title{
Exposure to Methamphetamine During First and Second Half of Prenatal Period and Its Consequences on Cognition After Long- Term Application in Adulthood
}

\author{
I. HREBÍČKOVÁ ${ }^{1}$, M. MALINOVÁ-ŠEVČÍKOVÁ ${ }^{1}$, E. MACÚCHOVÁ ${ }^{1}$, K. NOHEJLOVÁ ${ }^{1}$, \\ R. ŠLAMBEROVÁ ${ }^{1}$
}

${ }^{1}$ Department of Normal, Pathological and Clinical Physiology, Third Faculty of Medicine, Charles University in Prague, Prague, Czech Republic

Received March 16, 2014

Accepted August 11, 2014

\section{Summary}

It is known that psychostimulants including methamphetamine (MA) have neurotoxic effect, especially, if they are targeting CNS during its critical periods of development. The present study was aimed on evaluation of cognitive changes following scheduled prenatal MA exposure in combination with long-term exposure in adulthood of male rats. Two periods of gestation were targeted: $1^{\text {st }}$ half - the embryonic day (ED) $1-11$ and $2^{\text {nd }}$ half - ED 12-22. Rat mothers received subcutaneously a daily injection of MA $(5 \mathrm{mg} / \mathrm{kg})$ or saline (SAL, $1 \mathrm{ml} / \mathrm{kg}$ ) throughout scheduled periods. Male offspring were tested for cognitive changes in the Morris Water Maze (MWM) in adulthood. Each day of the experiment animals received an injection of MA $(1 \mathrm{mg} / \mathrm{kg})$ or SAL $(1 \mathrm{ml} / \mathrm{kg})$ during 12 days. Our results demonstrated that in the group of animals exposed to the drug during ED 1-11, neither prenatal MA exposure, nor adult MA treatment changed the performance in the MWM test. Only the velocity was increased in group with long-term MA treatment (SAL/MA and MA/MA). In the group of animals exposed to the drug during ED 12-22, rats exposed to MA prenatally and also in adulthood (MA/MA) swam faster but learned the position of the platform slower in the Place Navigation Test than animals exposed to SAL in adulthood (MA/SAL). In the Probe Test, MA/SAL had decreased velocity and swam shorter distance than MA/MA or SAL/SAL rats suggesting increased floating of these animals. In the Memory Retention Test, SAL/MA rats swam shorter distance than SAL/SAL or MA/MA animals suggesting changes in used strategies in memory recall. As conclusion, our results suggest differences in the effect of combination of prenatal and adult exposure to MA. These effects further depend on the stage of CNS development and schedule of MA exposure affecting intrauterine development in male rats.

\section{Key words}

Methamphetamine • Gestation period • Spatial learning • Morris Water Maze

\section{Corresponding author}

R. Šlamberová, Department of Normal, Pathological and Clinical Physiology, Third Faculty of Medicine, Ke Karlovu 4, 12000 Prague 2, Czech Republic. Fax: + 420 224902750. E-mail: rslamber@If3.cuni.cz

\section{Introduction}

Methamphetamine (MA) addiction in women during pregnancy is an alarming problem in developed countries all over the world (Williams et al. 2003). In general, the drugs do not only threaten women's health but also normal development of their children. Most of the abused drugs easily cross both the placenta and the fetal immature blood-brain barrier and they are present in maternal milk during lactation period (Dattel 1990). As a result of the exposure in prenatal and early postnatal periods, serious morphological, physiological and/or behavioral changes of the fetus follow, and may persist until adulthood (Chang et al. 2004). The number of children prenatally exposed to addictive substances grows every year (Williams et al. 2003).

The effect of MA exposure during prenatal CNS development depends upon many factors and the key role belongs to the gestational stages (Wilson et al. 1996). Consequences include reduction in the volume of several brain structures, such as hippocampus, dentate gyrus and 
striatum (Bubeníková-Valešová et al. 2009, Chang et al. 2004, Šlamberová et al. 2006), followed by long-term cognitive deficits, e.g., impairment in spatial learning and memory (Chang et al. 2004). A number of studies describe correlation between schedule and dose of MA administration. Acuff-Smith et al. (1996) investigated the effect of high and low MA doses exposure at different periods of gestation. High doses of MA (15 and $20 \mathrm{mg} / \mathrm{kg}$ ) administered in early days of gestation (embryonic day (ED); ED 7 to ED 12) impaired spatial learning and memory in the Morris Water Maze (MWM), while lower doses (5 and $10 \mathrm{mg} / \mathrm{kg}$ ) had no effect on cognition. In contrast, exposure between ED 13 and ED 18 in a variety of doses $(5,10,15,20 \mathrm{mg} / \mathrm{kg})$ does not affect spatial learning and memory (Acuff-Smith et al. 1996). Other study (Vorhees et al. 2000) showed that administration of MA $(5,10,15 \mathrm{mg} / \mathrm{kg})$ to rats during early postnatal period (postnatal day (PD); PD 1 to PD 10) does not induce any cognitive changes. In contrast, later exposure (PD 11 to PD 20) produces long-lasting impairment in spatial learning abilities (Williams et al. 2003).

Since regions of the brain mature at different rates, it is possible that exposure to MA during specific period induces certain impairment (Rice and Barone 2000, Williams et al. 2003). In rats, neural tube is complete at approximately ED 10.5-11. Interruption of neural developments during this early period can result in severe abnormalities of the brain and spinal cord (DeSesso et al. 1999). In the $2^{\text {nd }}$ week of gestation, specific areas of the CNS begin to form with the neurogenesis and migration of cells in the forebrain, midbrain and hindbrain. The $2^{\text {nd }}$ half of gestation is associated with organogenesis and development of the brain structures of the CNS associated with the higher nerve functions, such as cognition (Clancy et al. 2007, Rice and Barone 2000). The hippocampus, a brain structure important for cognitive functions, is developing and remodeling in rats on ED 14 and continues until PD 19. These periods are analogous to human hippocampal development during the $2^{\text {nd }}$ and $3^{\text {rd }}$ trimester of gravidity (Iaria et al. 2003, Rice and Barone 2000).

Our previous studies demonstrated increased sensitization to acute dose of MA $(1 \mathrm{mg} / \mathrm{kg})$ applied in adulthood after prenatal MA exposure (Bernášková et al. 2011, Schutová et al. 2009, Šlamberová et al. 2008, Šlamberová et al. 2011). This effect was linked to the increased dopamine levels in the nucleus accumbens (Bubeníková-Valešová et al. 2009). The purpose of the present study was to examine the effect of MA exposure on spatial learning and memory in adult male rats prenatally exposed to the same drug throughout the first (ED 1-11) and the second (ED 12-22) half of gestation. In order to test the cognitive deficits, we have used the hidden platform acquisition test in the MWM, one of the most widely used tasks in behavioral neuroscience for studying the psychological processes and neural mechanisms of spatial learning and memory (Morris et al. 1982).

\section{Methods}

The procedures of animal research used in this study were reviewed and approved by the Institutional Animal Care and Use Committee and is in agreement with the Czech Government Requirements under the Policy of Humans Care of Laboratory Animals (No. 246/1992) and with the subsequent regulations of the Ministry of Agriculture of the Czech republic.

\section{Prenatal care}

Adult female albino Wistar rats $(250-300 \mathrm{~g})$ were purchased from Anlab (Czech Republic, bread by Charles River Laboratories International, Inc.) and were housed in groups ( 5 rats/cage) and left undisturbed for a week in a temperature-controlled $\left(22-24^{\circ} \mathrm{C}\right)$ colony room with food and water ad libitum on 12:12 (light : dark) cycle. After acclimatization period, female rats were smeared by vaginal lavage to determine the phase of their estrous cycle. At the onset of the estrous phase of the estrous cycle females were housed overnight with sexually mature males. There was always one female and one male per cage. Next day the females were smeared for the presence of sperm and returned to their previous home cage. The day after impregnation was counted as day 1 of gestation (ED 1). Females were randomly assigned to MA-treated (MA) and saline-treated (SAL) groups. Physiological saline solution $(0.9 \% \mathrm{NaCl})$ and d-Methamphetamine hydrochloride were purchased from Sigma-Aldrich (Czech Republic).

The developmental differences between rats and humans were taken into account: birth in humans corresponds to the postnatal day (PD) 10-12 in rats (Clancy et al. 2007). In order to correspond with the first and the second trimester of pregnancy in humans, MA was administered during the first half (ED 1-11) and the second half of gestation (ED 12-22), respectively. MA was administered subcutaneously (s.c.) in a dose of 
$5 \mathrm{mg} / \mathrm{kg} /$ day. The choice of dose was based on the findings that fetal brain concentration of MA administered to pregnant female rats is comparable with that found in fetus of drug-abusing women (Acuff-Smith et al. 1996). SAL was injected at the same time and volume as MA (1 mg/kg/day).

\section{Postnatal care}

On ED 21 females were separated to maternity cages. The day of delivery was counted as PD 0. On PD 1 , number of pups in each litter was adjusted to 12 . Pups were cross-fostered so that each mother raised 6 MAexposed pups (usually 3 males and 3 females) and 6 SAL-exposed pups (usually 3 males and 3 females). In the same time, all prenatally MA-exposed pups were tattooed with black India ink into the left foot and all prenatally SAL-exposed pups into the right foot for future identification. On PD 21, pups fostered by MA-treated mothers were ear-punched in the left ear and pups fostered by SAL-treated mothers in the right ear for farther identification. After that pups were weaned and housed in groups, separated according to sex. Animals were left undisturbed until adulthood. 32 litters, 8 in each of four groups scheduled MA-exposure (ED 1-11 and ED 12-22) and SAL-exposure (ED 1-11 and ED 12-22), were used in the experiment. Only adult males were further used in the experiment. Always only two males from litter were used, one MA-exposed and one SA-exposed, to prevent litter effect. The rest of animals were used in other experiments.

According the prenatal exposure schedule and the adult drug administration 8 groups formed to test changes in cognition (Table 1).

Table 1. Assignment of the animals to individual groups according to schedule and type of prenatal treatment versus long-term treatment in adulthood.

\begin{tabular}{|c|c|c|c|c|c|}
\hline & & \multicolumn{2}{|c|}{$\begin{array}{c}1^{\text {st }} \text { half of gestation period, } \\
\text { ED 1-11 }\end{array}$} & \multicolumn{2}{|c|}{$\begin{array}{c}2^{\text {nd }} \text { half of gestation period, } \\
\text { ED } 12-22\end{array}$} \\
\hline & & $\begin{array}{c}\text { MA } \\
(5 \mathrm{mg} / \mathrm{kg} / \mathrm{day})\end{array}$ & $\begin{array}{c}\text { SAL } \\
(1 \mathrm{ml} / \mathrm{kg} / \text { day })\end{array}$ & $\begin{array}{c}\text { MA } \\
(5 \mathrm{mg} / \mathrm{kg} / \text { day })\end{array}$ & $\begin{array}{c}\text { SAL } \\
(1 \mathrm{ml} / \mathrm{kg} / \text { day })\end{array}$ \\
\hline \multirow{2}{*}{$\begin{array}{l}\text { Adult long- } \\
\text { term treatment } \\
\text { (12 days) }\end{array}$} & $\begin{array}{l}M A \\
(1 \mathrm{mg} / \mathrm{kg})\end{array}$ & $\mathrm{MA} / \mathrm{MA}, \mathrm{n}=8$ & $\mathrm{SAL} / \mathrm{MA}, \mathrm{n}=8$ & MA/MA, $n=8$ & $\mathrm{SAL} / \mathrm{MA}, \mathrm{n}=8$ \\
\hline & $\begin{array}{l}S A L \\
(1 \mathrm{ml} / \mathrm{kg})\end{array}$ & MA/SAL, $n=8$ & $\mathrm{SAL} / \mathrm{SAL}, \mathrm{n}=8$ & $\mathrm{SAL} / \mathrm{MA}, \mathrm{n}=8$ & $\mathrm{SAL} / \mathrm{SAL}, \mathrm{n}=8$ \\
\hline Total number of & inimals & & & & \\
\hline
\end{tabular}

Total number of male rats used in experiment was 64, individual group accounted 8 animals. Adult long-term treatment started on the day of the beginning of MWM tests and continues for subsequent 12 days. The MA dose of $1 \mathrm{mg} / \mathrm{kg}$ was used for long-term application because it does not cause stereotypies, unlike the dose of $5 \mathrm{mg} / \mathrm{kg}$ used during gestation (Šlamberová et al. 2006).

\section{Evaluation of cognition in the Morris Water Maze}

The male offspring ( $\mathrm{n}=64$, Table 1$)$ were tested in adulthood (PD 60-90) for learning and memory in the MWM (Schutová et al. 2008). The MWM tests had three phases: Place Navigation Test (Learning) on Days 1-6, Probe Test on Day 8 and Memory Retention Test (Memory) on Day 12. During these subsequent 12 days animals received treatment with $\mathrm{MA}(1 \mathrm{mg} / \mathrm{kg})$ or SAL $(1 \mathrm{ml} / \mathrm{kg})$. The low dose of MA was chosen because it does not induce stereotypies that could affect swimming, unlike the higher dose of $5 \mathrm{mg} / \mathrm{kg}$ used during gestation (Šlamberová et al. 2006).

The Place Navigation Test of hidden platform acquisition was chosen to evaluate spatial learning. The platform was placed in stable position $1 \mathrm{~cm}$ under the water surface, invisible for the swimming rats. Four starting positions were assigned on the rim of the maze: north $(\mathrm{N})$, south $(\mathrm{S})$, east $(\mathrm{E})$, west $(\mathrm{W})$, dividing the maze into four quadrants, where platform was placed in $\mathrm{N}-\mathrm{W}$ quadrant. Various pictures were hanging on the walls and could be used by rats as extra-maze cues. The Place Navigation Test was performed during 6 days of the experiment. An animal was expected to find the platform within the limit of $60 \mathrm{~s}$. If the animal was not able to found platform as assigned, it was manually guided to the platform, where it remained until next trial. 
Each rat performed 8 trials daily starting from 4 different positions with $30 \mathrm{~s}$ intervals in between. Rats' performance was tracked automatically using a videotracking system EthoVision XT7 (Noldus Information Technology, The Netherlands). The following parameters were evaluated: latency to reach the hidden platform [s], distance traveled $[\mathrm{cm}]$, search error $[\mathrm{cm}]$ (a measure of proximity to the escape platform though the trial) and velocity of swimming $[\mathrm{cm} / \mathrm{s}]$. After finishing all trials in the experimental day, animal was dried by towel and injected either by MA $(1 \mathrm{mg} / \mathrm{kg})$ or SAL $(1 \mathrm{ml} / \mathrm{kg})$ according to the group assigned (Table 1). Thereafter animal was returned to its home cage and remained undisturbed till the next experiment day.

In the Probe Test, which was conducted on the $8^{\text {th }}$ day of the experiment, the platform was removed and the animal was left to swim in the maze for $60 \mathrm{~s}$. The start position was north $(\mathrm{N})$, which is the nearest location to previous platform position. The following parameters were recorded: distance travelled $[\mathrm{cm}]$, the velocity of swimming $[\mathrm{cm} / \mathrm{s}]$, number of crossing of the former position of the platform, number of crossing and the duration of presence in the quadrant where the platform was located [s], number of crossing and the duration of presence in the opposite quadrant [s].

The Memory Retention Test was performed on the $12^{\text {th }}$ day of the experiment and the rat supposed to find the platform located in the same position as in the learning phase within $60 \mathrm{~s}$. Each rat was performed to 8 trials starting from four different positions. The following parameters were evaluated: latency to reach the hidden platform [s], distance traveled [cm], search error $[\mathrm{cm}]$ and velocity of swimming $[\mathrm{cm} / \mathrm{s}]$.

Swim paths for each rat during the Place Navigation Test were manually analyzed, so that predominating strategy in each trial was identified and frequency of the following search strategies was recorded on Days 1, 3, 6 and 12. Study of (Janus 2004) demonstrated that strategies of swimming are being considered as important sign of animal's ability to show the spatial learning and not just a random searching for the platform. Therefore, the following strategies were recognized: 1) Thigmotaxis (wall-hugging) - a persistent swim along the wall of the pool that could include sporadic swims towards the centre of the pool, 2) Random search - swimming over the entire area of the pool in straight swims or in wide circular swims, 3) Scanning - swimming over the central area of the pool,
4) Focal search in an incorrect quadrant - direct swim to an incorrect quadrant of the pool followed by loops and turns there, 5) Focal search in the target quadrant - direct swim to an correct quadrant of the pool followed by loops and turns there, 6) Spatial search - a direct swim path to the platform.

\section{Statistical methods}

Two-way ANOVA (Prenatal exposure $x$ Treatment in adulthood) with multilevel repeated measure (Days $x$ Trials/day) was used to analyze the data from the Place Navigation Test and Retention Memory Test. Two way ANOVA (Prenatal exposure $x$ Treatment in adulthood) was used to analyze the data from the Probe Test. Bonferroni test was used for post-hoc comparisons. $\chi^{2}$ test was used to analyze the occurrence of the search strategies. Differences were considered significant, if $\mathrm{p}<0.05$.

\section{Results}

\section{Place Navigation Test}

In the group of adult male rats exposed in ED 111, neither prenatal MA exposure nor MA treatment in adulthood affected the latencies $[\mathrm{F}(5,135)=1.12 ; \mathrm{p}=0.36]$, distances traveled $[\mathrm{F}(5,140)=1.47 ; \mathrm{p}=0.20]$ and search errors $[\mathrm{F}(5,140)=0.80 ; \mathrm{p}=0.55]$ in the Place Navigation Test. The only difference was found in the velocity to reach the hidden platform (Fig. 1). MA treatment in adulthood increased the velocity of swimming when compared to SAL-treated controls and this effect was independent on the prenatal drug exposure $[\mathrm{F}(1,28)=$ 8.02; $<<0.01]$.

In the group of adult male rats exposed in ED $12-22$, there were no differences between groups in latency $[\mathrm{F}(5,140)=2.27 ; \mathrm{p}=0.07]$, distance traveled $[F(5,140)=2.72 ; p=0.06]$ or the search error $[F(5,140)=$ 2.24; $\mathrm{p}=0.07]$. On the other hand, the velocity of swimming (Fig. 2) was increased by adult MA treatment, but only in prenatally MA-exposed and not in prenatally SAL-exposed animals $[\mathrm{F}(1,28)=4.47 ; \mathrm{p}<0.05]$.

\section{Probe Test}

In the group of adult male rats exposed in ED 111, neither prenatal MA exposure, nor adult MA treatment changed the performance of the Probe Test. In the group of adult male rats exposed in ED 12-22, there was an interaction between prenatal exposure and adult 


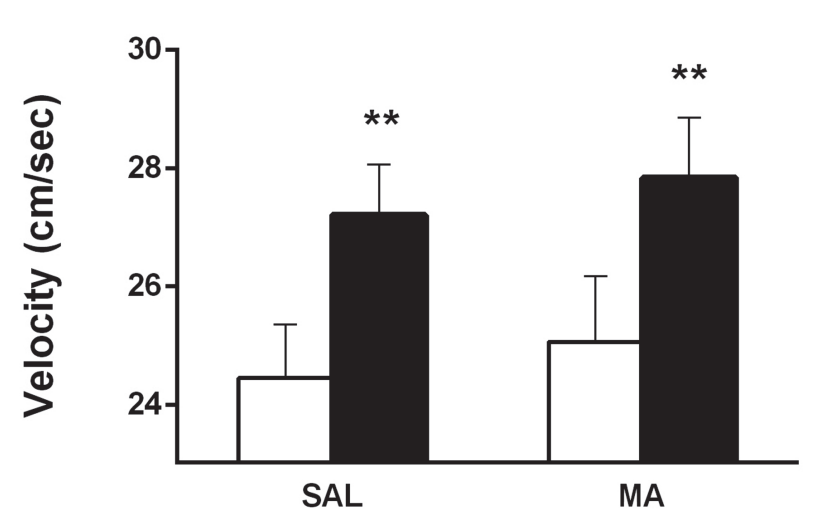

prenatal exposure

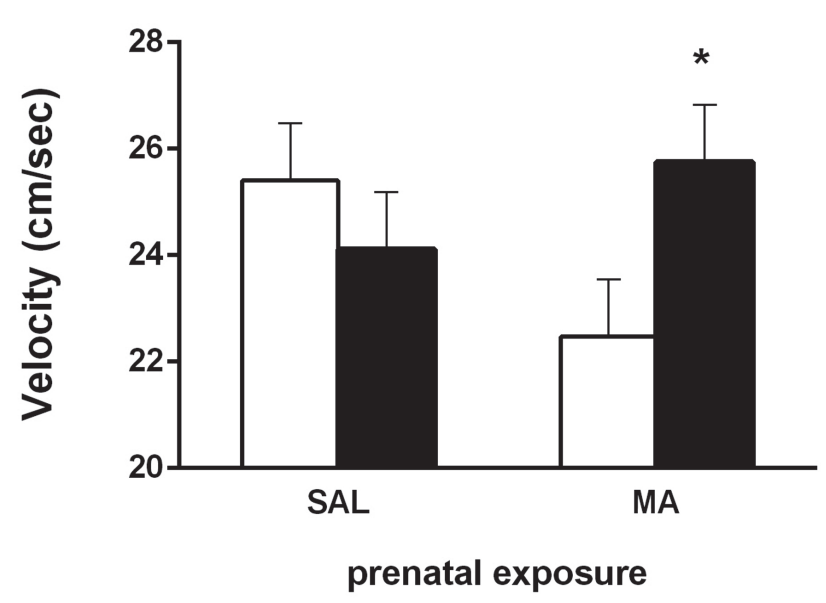

treatment in the velocity $[\mathrm{F}(1,28)=4.91 ; \mathrm{p}<0.05]$ and in distance traveled $[\mathrm{F}(1,28)=4.97 ; \mathrm{p}<0.05]$. Animals prenatally exposed to MA and treated in adulthood with SAL swam slower and swam shorter distance than prenatally SAL-exposed rats treated in adulthood with SAL or prenatally MA-exposed rats treated in adulthood with MA. However, as a matter the number of crossing of former platform placement or swimming in correct or incorrect quadrant, there were no statistical differences.

\section{Memory Retention Test}

In the group of adult male rats exposed in ED 111, there were no significant differences induced by prenatal exposure or adult treatment in the latency $[F(7,196)=0.68 ; p=0.69]$ (Fig. 3A), the distance traveled $[\mathrm{F}(7,196)=0.62 ; \quad \mathrm{p}=0.74] \quad$ (Fig. 3B), search error $[\mathrm{F}(7,196)=0.47 ; \mathrm{p}=0.86]$ or velocity $[\mathrm{F}(7,196)=0.42$; $\mathrm{p}=0.89]$.

In the group of adult male rats exposed in ED 12-22, there was an interaction between prenatal exposure and adult treatment in the latency $[\mathrm{F}(1,28)=$ adult treatment

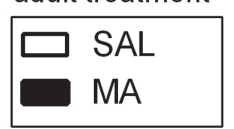

Fig. 1. Effect of prenatal and adult $M A$ exposure throughout ED 1-11 on velocity of swimming in the Place Navigation Test. Results are presented as mean \pm SEM, $n=8$; $* * p<0.01$ - main effect of long-term MA treatment in adulthood: MA groups swam faster than SAL-treated animals.

adult treatment

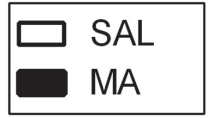

Fig. 2. Effect of prenatal and adult $M A$ exposure throughout ED 12-22 on velocity of swimming in the Place Navigation Test. Results are presented as mean \pm SEM, $n=8$; $* p<0.05-$ MA/MA swam faster than MA/SAL.
4.47; $\mathrm{p}<0.05]$, the distance traveled $[\mathrm{F}(1,28)=7.97$; $\mathrm{p}<0.01]$ and search error $[\mathrm{F}(1,28)=4.35 ; \mathrm{p}<0.05]$. As shown in Figure 4, prenatally SAL-exposed animals with adult MA treatment had shorter latencies (A), swam shorter distance (B) and did less search errors than prenatally SAL-exposed rats treated in adulthood with SAL. Moreover, prenatally MA-exposed animals treated in adulthood with SAL swam shorter distance than prenatally SAL-exposed animals with adult SAL treatment. The velocity of swimming was not changed in the Memory Retention Test $[\mathrm{F}(7,196)=1.40 ; \mathrm{p}=0.21]$.

\section{Search strategies}

In the group of adult male rats exposed in ED 111, the strategies of swimming to find the hidden platform differed based on the prenatal and adult MA application and changed as the time of experiment progressed.

The strategies used in animals exposed to MA in ED 1-11 differed only in the day 6 and 12 of the MWM. Specifically, animals exposed in adulthood to the same 
A

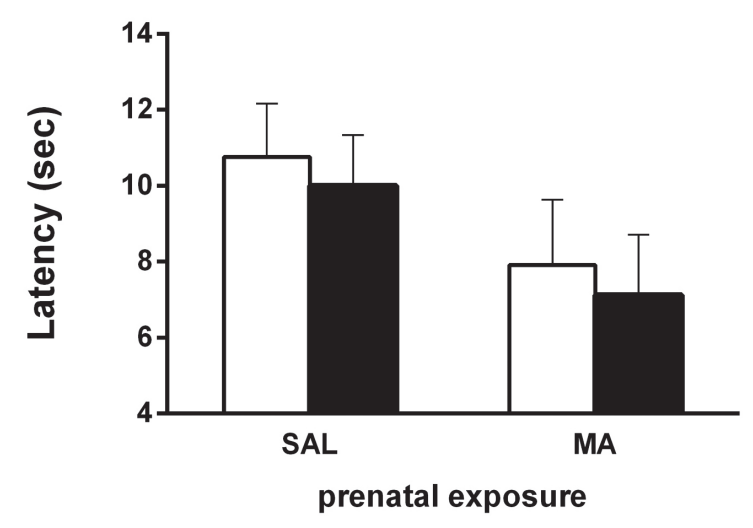

B
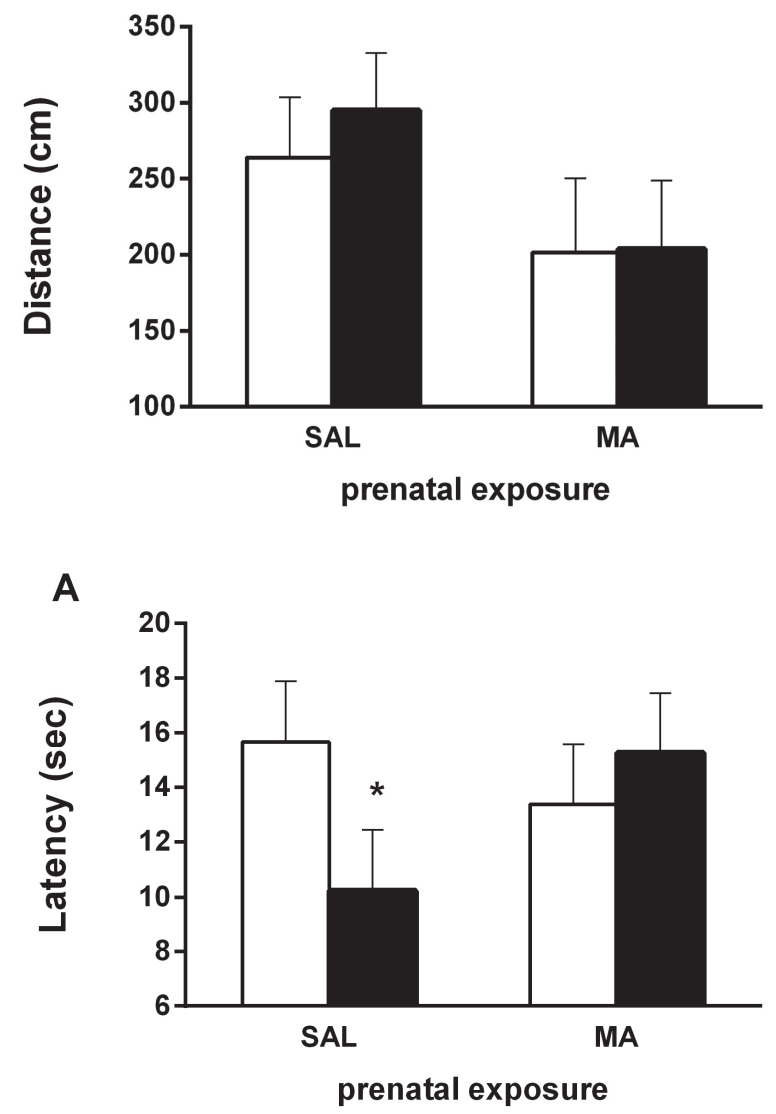

B

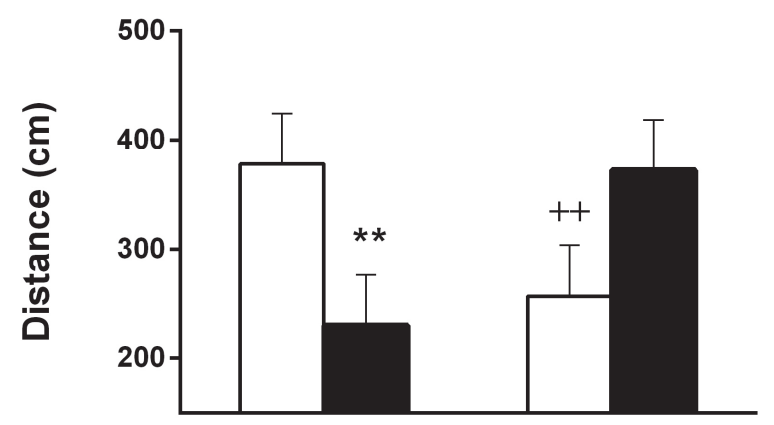

SAL prenatal exposure adult treatment

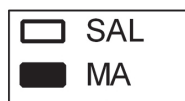

Fig. 3. Effect of prenatal and adult MA exposure throughout ED 1-11 on performance in the Memory Retention Test. A. Latency of platform acquisition. B. Distance traveled. Results are presented as mean \pm SEM, $\mathrm{n}=8$. adult treatment

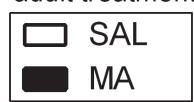

Fig. 4. Effect of prenatal and adult $M A$ exposure throughout ED 12-22 on performance in the Memory Retention Test. A. Latency of platform acquisition. B. Distance traveled. Results are presented as mean \pm SEM, $\mathrm{n}=8 ; * \mathrm{p}<0.05-$ SAL/MA had shorter latencies than SAL/SAL; ** $\mathrm{p}<0.01$ - SAL/MA swam shorter distance than SAL/SAL; ++ $p<0.01$ - MA/SAL swam shorter distance than SAL/SAL. 
treatment as prenatally $\{\mathrm{SAL} / \mathrm{SAL}=60 \%$; MA/MA $=$ $64 \%$ swam on Day 6 directly to the hidden platform than animals that received in adulthood the opposite treatment as prenatally $\{\mathrm{SAL} / \mathrm{MA}=38 \%$; $\mathrm{MA} / \mathrm{SAL}=$ $46 \%\}[\chi 2=12.49 ; \mathrm{p}<0.01]$. In addition, prenatally SALexposed animals $\{\mathrm{SAL} / \mathrm{SAL}=15 \%$; SAL/MA $=25 \%$ \} swam more often in the opposite quadrant than prenatally MA-exposed rats $\{\mathrm{MA} / \mathrm{SAL}=6 \% ; \mathrm{MA} / \mathrm{MA}=7 \%\}$ $[\chi 2=11.97 ; \mathrm{p}<0.01]$.

In the group of adult male rats exposed in ED 12-22, there were more significant differences in used strategies in the MWM. On Day 1, while prenatally MAexposed rats used rather thigmotaxis $\{\mathrm{SAL} / \mathrm{SAL}=17 \%$; $\mathrm{SAL} / \mathrm{MA}=11 \% ; \mathrm{MA} / \mathrm{SAL}=38 \% ; \mathrm{MA} / \mathrm{MA}=16 \%\}$ $[\chi 2=16.41 ; \mathrm{p}<0.001]$ or scanning $\{\mathrm{SAL} / \mathrm{SAL}=25 \%$; $\mathrm{SAL} / \mathrm{MA}=22 \% ; \mathrm{MA} / \mathrm{SAL}=9 \% ; \mathrm{MA} / \mathrm{MA}=30 \%\}$ $[\chi 2=8.59 ; \mathrm{p}<0.05]$, prenatally SAL-exposed rats swam more often in the opposite quadrant $\{\mathrm{SAL} / \mathrm{SAL}=16 \%$; $\mathrm{SAL} / \mathrm{MA}=23 \% ; \mathrm{MA} / \mathrm{SAL}=6 \%$; MA/MA $=11 \%\}$ $[\chi 2=8.53 ; \mathrm{p}<0.05]$ on Day 1 .

On Day 3, animals treated in adulthood with SAL swam more often directly to the hidden platform than animals treated in adulthood with $\mathrm{MA}\{\mathrm{SAL} / \mathrm{SAL}=$ $17 \%$; SAL/MA $=9 \%$; MA/SAL $=34 \%$; MA/MA $=$ $14 \%\}[\chi 2=14.97 ; \mathrm{p}<0.01]$.

On Day 6, in the Place Navigation Test, significant interaction between prenatal and adult MA application was in animals which used rather direct swimming to hidden platform than other animals $\{\mathrm{SAL} / \mathrm{MA}=52 \%$; MA/SAL $=47 \%$; SAL/SAL $=31 \%$; MA/MA $=25 \%\}[\chi 2=12.83 ; \mathrm{p}<0.01]$, which swam significantly more often in correct quadrant $\{\mathrm{MA} / \mathrm{MA}=$ $14 \% ; \mathrm{MA} / \mathrm{SAL}=11 \% ; \mathrm{SAL} / \mathrm{MA}=2 \% ; \mathrm{SAL} / \mathrm{SAL}=$ $0 \%\}[\chi 2=14.81 ; \mathrm{p}<0.01]$ or using scanning $\{\mathrm{MA} / \mathrm{MA}=$ $22 \%$; SAL $/ \mathrm{SAL}=23 \%$; MA/SAL $=9 \%$; SAL $/ \mathrm{MA}=$ $9 \%\}[\chi 2=8.45 ; \mathrm{p}<0.05]$.

On Day 12, in the Memory Retention Test, there were significant interactions between prenatal exposure and MA treatment in adulthood in used strategies, animals used direct swimming to hidden platform $\{\mathrm{SAL} / \mathrm{MA}=61 \% ; \mathrm{MA} / \mathrm{SAL}=47 \%$; MA/MA $=39 \%$; $\mathrm{SAL} / \mathrm{SAL}=36 \%\}$ than control animals $[\chi 2=9.62$; $\mathrm{p}<0.05]$, which used scanning to find platform $\{\mathrm{SAL} / \mathrm{SAL}=27 \%$; MA/MA $=17 \%$; MA $/ \mathrm{SAL}=13 \%$; $\mathrm{SAL} / \mathrm{MA}=6 \%\}[\chi 2=10.67 ; \mathrm{p}<0.05]$.

\section{Effect of gestational period}

Because our results suggested that there might be differences induced by prenatal MA exposure on the measures between first and second half gestational application, we decided to run additional statistical analysis that would compare results between the two gestational periods (ED 1-11 vs. ED 12-22). Since the most statistical differences were present in the Memory Retention Test, a Three Way ANOVA (Prenatal exposure $\mathrm{x}$ Treatment in adulthood $\mathrm{x}$ Gestational period) with repeated measure (trials) was further used to analyze the data from the Memory Retention Test.

As shown in Figure 5, animals exposed to the prenatal treatment within the $2^{\text {nd }}$ half of gestation had longer latencies $[\mathrm{F}(1,56)=11.99 ; \mathrm{p}<0.01]$, swam longer distance $[F(1,56)=4.63 ; \mathrm{p}<0.05]$, displayed greater search errors $[\mathrm{F}(1,56)=14.67 ; \mathrm{p}<0.001]$ and swam slower $[F(1,56)=7.48 ; \mathrm{p}<0.01]$ than animals exposed to the prenatal treatment within the $1^{\text {st }}$ half of gestation.

As a matter of strategies used on Day 12 of the experiment, animals exposed to injections within $1^{\text {st }}$ half of the gestation used less scanning strategy \{ED 1-11 $=$ $6 \%$; ED 12-22 = $16 \%\}[\chi 2=12.73 ; \mathrm{p}<0.001]$, searched less in the opposite quadrant $\{$ ED $1-11=15 \%$; ED 12-22 $=33 \%\}[\chi 2=22.77 ; \mathrm{p}<0.0001]$, and on the other hand used more searching in the correct quadrant $\{$ ED 1-11 $=$ $13 \%$; ED 12-22 = 5\% $\quad[\chi 2=8.46 ; \mathrm{p}<0.01]$ and used more often direct swimming $\{$ ED $1-11=66 \%$; ED 12-22 $=46 \%\}[\chi 2=21.42 ; \mathrm{p}<0.0001]$ when compared to animals exposed to injections within $2^{\text {nd }}$ half of the gestation.

\section{Discussion}

The aim of the present study was to determine the effect of long-term MA treatment in adulthood $(1 \mathrm{mg} / \mathrm{kg})$ on cognition in adult male rats prenatally exposed to the same drug $(5 \mathrm{mg} / \mathrm{kg})$ throughout the $1^{\text {st }}$ (ED 1-11) and the $2^{\text {nd }}$ half (ED 12-22) of their prenatal period.

First, our results show that prenatal MA exposure in either of the gestation periods did not affect the latency, search error and length of the trajectory in the Place Navigation Test. These results are in accordance with our previous studies, in which prenatal MA exposure throughout the gestation at a dose of $5 \mathrm{mg} / \mathrm{kg}$ daily did not influence learning in the MWM (Macúchová et al. 2013, Schutová et al. 2008).

The Probe test is a good way of analysis of the memory recall quality. Data from this type of test showed, that animals exposed to MA throughout ED 1222 swam slower and swam shorter distance, which 
A

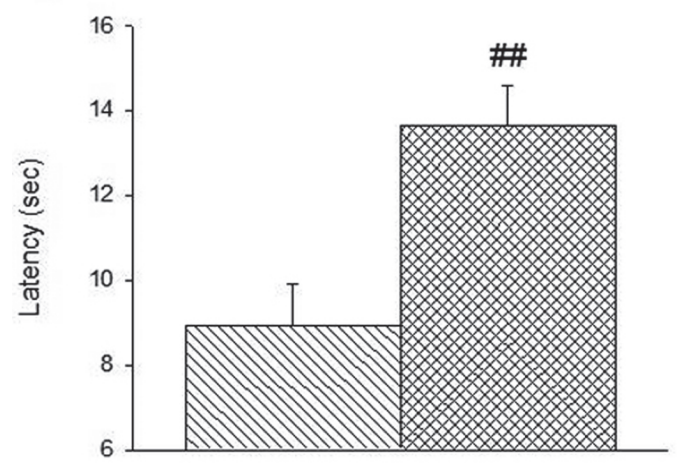

C

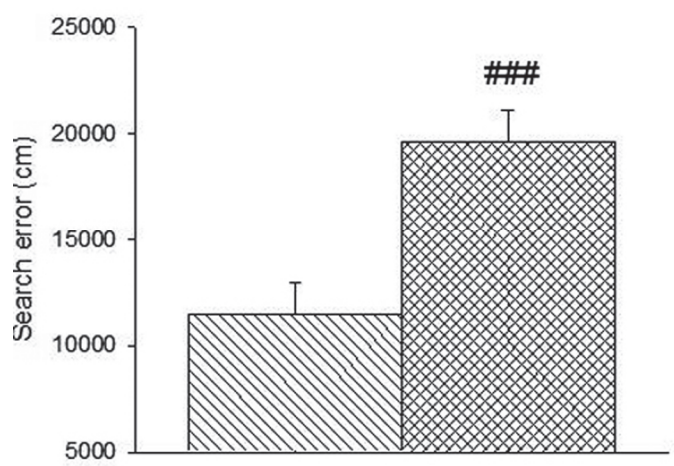

B

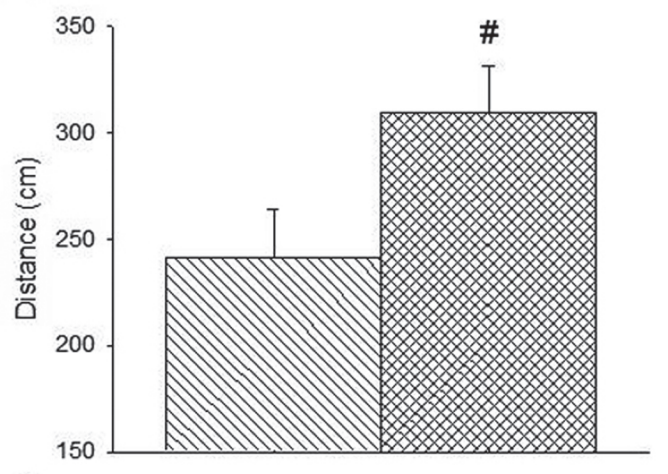

D

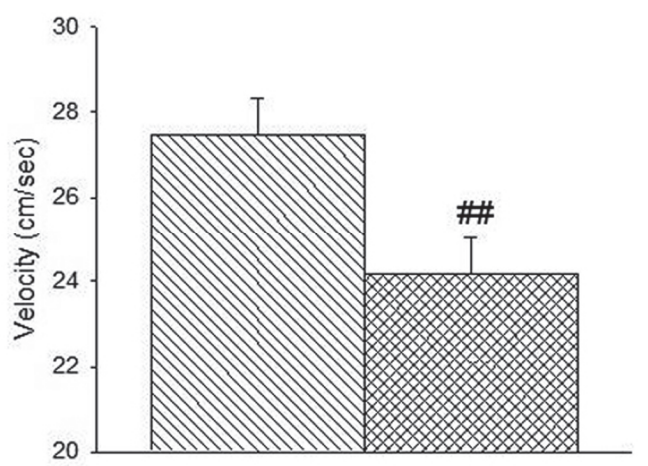

Fig. 5. Effect of prenatal and adult MA exposure throughout ED 1-11 vs. ED 12-22 on performance in the Memory Retention Test. A. Latency of platform acquisition. B. Distance traveled. C. Search error. D. Velocity. Results are presented as an average of all groups in each of the injection schedules; mean $\pm S E M, n=32$; $\# p<0.05-$ animals exposed in ED 12-22 had longer distances than animals exposed in ED 1-11; \#\# $p<0.01$ - animals exposed in ED 12-22 had longer latencies and swam slower than animals exposed in ED 111; \#\#\# $\mathrm{p}<0.001$ - animals exposed in ED 12-22 displayed greater search errors than animals exposed in ED 1-11.

disagrees with our previous study, where no effect of prenatal MA exposure on performance was found in male rats (Schutová et al. 2009). On the other hand, our recent study of Macúchová et al. (2013) showed that prenatal MA-exposed females had changed performance on Probe trials in comparison with the control groups. This discrepancy may be assigned to sex differences. Therefore, our data suggest that the prenatal MA exposure may impair only learning of animals exposed throughout the $2^{\text {nd }}$ half of their prenatal period.

Second, the fact that MA treatment in adulthood had no significant effect on the latency in the Place Navigation Test, can be explained by increased swimming velocities in rats with adult MA-exposure. We found an effect of MA treatment in adulthood on the velocity of swimming during learning period of the MWM test, which seems to have the positive correlation to the motivation of the animals to find the platform (Lubbers et al. 2007). The meso-accumbens dopamine system, which can be mediated by the motivation, might be affected by MA application in adulthood (Salamone and Correa 2002). In this study, MA-treated rats in adulthood swam faster than SAL groups regardless of the prenatal treatment, which does correspond with our previous results (Schutová et al. 2009). Therefore, the increased swimming velocity suggests that MA/MA and SAL/MA groups prenatally exposed throughout ED 1-11 and MA/MA group exposed throughout ED 12-22 had increased motivation caused by long-term MA application in adulthood. Searching trajectories of rats with MA application in adulthood did not change. Possible reason is that long-term MA treatment following prenatal application of the same drug increases general locomotor activity as we demonstrated in our previous study of Schutová et al. (2010). Similar effect was seen when experimental animals were treated by another psychostimulants following prenatal MA exposure (Hrubá et al. 2012, Perris et al. 1992).

Third, we found that prenatal MA exposure did not have effect on spatial memory in animals exposed throughout the $1^{\text {st }}$ half of their prenatal period (ED 1-11), which is in accordance with study of Acuff-Smith et al. 
(1996), who also showed that low doses of MA (5 or 10 $\mathrm{mg} / \mathrm{kg}$ ) administered prenatally did not have effect on spatial memory in the MWM. The animals exposed to MA throughout the $2^{\text {nd }}$ half of their prenatal period (ED 12-22) had shorter distances travelled than rats with prenatal exposure to SAL. This discrepancy between the present work and the work of Acuff-Smith et al. (1996) seems to be in the scheduling of injection.

We found an effect of chronic MA treatment in the Memory Retention Test in animals exposed prenatally to SAL in ED 12-22. Animals had significantly shorter latencies, swam shorter distances and had lower search error. The analysis of search error may be the best to reflect the accuracy of spatial learning, because studies showed that two animals may have escape latencies and/or distances travelled almost identical, but their performance can actually differ markedly (Janus 2004, Schutová et al. 2009). While one of the animals searches for the platform relatively close to it, the other searches in quadrant distant to the hidden platform randomly and finds the platform accidentally. Results of search strategy analysis demonstrated that group prenatally exposed to SAL with the MA treatment in adulthood (SAL/MA) swam significantly more often directly to the hidden platform than other experimental groups of animals. These results suggest that animals with MA treatment in adulthood memorized the location of the platform most accurately. There are some studies investigating the effect of chronic MA applications, in which acute MA in lower doses (0.1-0.4 $\mathrm{mg} / \mathrm{kg})$ was shown to produce improvements in cognitive processing, when given to drug-naïve subjects (Grilly and Loveland 2001, Kornetsky et al. 1959). In experimental animals, acute treatment with MA in dose of $3 \mathrm{mg} / \mathrm{kg}$ disorders spatial and non-spatial memory was accompanied by loss of dopaminergic and serotonergic nerve terminals in the brain (Grilly and Loveland 2001, Schroder et al. 2003). Other study of Camarasa et al. (2010) demonstrated that repeated MA treatment in dose of $10 \mathrm{mg} / \mathrm{kg}$ induced an impairment of spatial and non-spatial memory in male rats, which persisted for at least 7 days after the withdrawal of MA. Our test of memory was performed 6 days after the end of the learning trials.

As a matter of schedule of MA exposure during prenatal development, our data support the statement that drugs administered during prenatal development affects those systems that are evolving at the time of application (Kellogg 1992). In general, regional development of the rodent brain proceeds on a timeline of days versus weeks to months in humans, although gross regional development of the brain of rodents and humans is similar (Rice and Barone 2000). On the other hand, the neurogenesis in rodents is different from humans because rodents have considerable postnatal development and humans have considerably more prenatal maturation of their nervous system (Squire 1992). Since regions of the brain mature at different rates it is possible that exposure to the drugs may produce effects during one developmental time period, but not another. If exposure occurs before or after an organ development, it is less vulnerable to change than if exposure occurs during the time of development of that organ (Atterberry et al. 1997, Rice and Barone 2000). It was shown that rat hippocampus, a brain structure responsible for spatial normal learning and memory, begins to develop on ED 14 and continues until postnatal day 19 (Bayer et al. 1993). Therefore, this period, which corresponds with the $2^{\text {nd }}$ and the $3^{\text {rd }}$ trimester of human pregnancy, may be more critical for the effect of MA on cognitive functions. This is supported with the present results showing that animals exposed to the prenatal treatment within $2^{\text {nd }}$ half of gestation (ED 12-22) had significantly longer latencies, swam longer distances, swam slower and displayed greater search errors than animals exposed in the $1^{\text {st }}$ half of gestation.

To sum up, the present study demonstrates that stage the prenatal development is crucial for determination the cognitive deficits induced by prenatal MA exposure. The present data help to better understand the neurobiological changes responsible for MA-induced alterations in cognitive functions.

\section{Conflict of Interest}

There is no conflict of interest.

\section{Acknowledgements}

This study was supported by grant \# GA 14-03708S from Grant Agency of the Czech Republic, project \# PRVOUK P34, GAUK 545612 and 260045/SVV/2014 from Charles University in Prague, and by project \# CSM7/CRP/2014 from Ministry of Education, Youth and Sports. 


\section{References}

ACUFF-SMITH KD, SCHILLING MA, FISHER JE, VORHEES CV: Stage-specific effect of prenatal dmethamphetamine exposure on behavioral and eye development in rats. Neurotoxicol Teratol 18: 199-215, 1996.

ATTERBERRY TT, BURNETT WT, CHAMBERS JE: Age-related differences in parathion and chlorpyrifos toxicity in male rats: target and nontarget esterase sensitivity and cytochrome P450-mediated metabolism. Toxicol Appl Pharmacol 147: 411-418, 1997.

BAYER SA, ALTMAN J, RUSSO RJ, ZHANG X: Timetables of neurogenesis in the human brain based on experimentally determined patterns in the rat. Neurotoxicology 14: 83-144, 1993.

BERNÁŠKOVÁ K, MATĚJOVSKÁ I, ŠLAMBEROVÁ R: Postnatal challenge dose of methamphetamine amplifies anticonvulsant effects of prenatal methamphetamine exposure on epileptiform activity induced by electrical stimulation in adult male rats. Exp Neurol 229: 282-287, 2011.

BUBENÍKOVÁ-VALEŠOVÁ V, KAČER P, SYSLOVÁ K, RAMBOUSEK L, JANOVSKÝ M, SCHUTOVÁ B, HRUBÁ L, ŠLAMBEROVÁ R: Prenatal methamphetamine exposure affects the mesolimbic dopaminergic system and behavior in adult offspring. Int J Dev Neurosci 27: 525-530, 2009.

CAMARASA J, RODRIGO T, PUBILL D, ESCUBEDO E: Memantine is a useful drug to prevent the spatial and nonspatial memory deficits induced by methamphetamine in rats. Pharmacol Res 62: 450-456, 2010.

CHANG L, SMITH LM, LOPRESTI C, YONEKURA ML, KUO J, WALOT I, ERNST T: Smaller subcortical volumes and cognitive deficits in children with prenatal methamphetamine exposure. Psychiatry Res 132: 95-106, 2004.

CLANCY B, FINLAY BL, DARLINGTON RB, ANAND KJS: Extrapolating brain development from experimental species to humans. Neurotoxicology 28: 931-937, 2007.

DATTEL BJ: Substance abuse in pregnancy. Semin Perinatol 14: 179-187, 1990.

DESESSO JM, SCIALLI AR, HOLSON JF: Apparent lability of neural tube closure in laboratory animals and humans. Am J Med Genet 87: 143-162, 1999.

GRILLY DM, LOVELAND A: What is a "low dose" of d-amphetamine for inducing behavioral effects in laboratory rats? Psychopharmacology (Berl) 153: 155-169, 2001.

HRUBÁ L, SCHUTOVÁ B, ŠLAMBEROVÁ R: Sex differences in anxiety-like behavior and locomotor activity following prenatal and postnatal methamphetamine exposure in adult rats. Physiol Behav 105: 364-370, 2012.

IARIA G, PETRIDES M, DAGHER A, PIKE B, BOHBOT VD: Cognitive strategies dependent on the hippocampus and caudate nucleus in human navigation: variability and change with practice. $J$ Neurosci 23: 5945-5952, 2003.

JANUS C: Search strategies used by APP transgenic mice during navigation in the Morris water maze. Learn Mem 11: 337-346, 2004.

KELLOGG CK: Benzodiazepines and the developing nervous system: laboratory findings and clinical implications. In: Maternal Substance Abuse and the Developing Nervous System. ZAGON IS, SLOTKIN TA (eds), Academic Press, San Diego, 1992, pp 283-321.

KORNETSKY C, MIRSKY AF, KESSLER EK, DORFF JE: The effects of dextro-amphetamine on behavioral deficits produced by sleep loss in humans. J Pharmacol Exp Ther 127: 46-50, 1959.

LUBBERS ME, VAN DEN BOS R, SPRUIJT BM: Mu opioid receptor knockout mice in the Morris Water Maze: a learning or motivation deficit? Behav Brain Res 180: 107-111, 2007.

MACÚCHOVÁ E, NOHEJLOVÁ-DEYKUN K, ŠLAMBEROVÁ R: Effect of methamphetamine on cognitive functions of adult female rats prenatally exposed to the same drug. Physiol Res 62 (Suppl 1): S89-S98, 2013.

MORRIS RG, GARRUD P, RAWLINS JN, O'KEEFE J: Place navigation impaired in rats with hippocampal lesions. Nature 297: 681-683, 1982.

PERRIS J, COLEMAN-HARDEE M, MILLARD WJ: Cocaine in utero enhances the behavioral response to cocaine in adult rats. Pharmacol Biochem Behav 42: 509-515, 1992.

RICE D, BARONE SJ: Critical periods of vulnerability for the developing nervous system: evidence from humans and animal models. Environ Health Perspect 108: 511-533, 2000. 
SALAMONE JD, CORREA M: Motivational views of reinforcement: implications for understanding the behavioral functions of nucleus accumbens dopamine. Behav Brain Res 137: 3-25, 2002.

SCHRODER N, O'DELL SJ, MARSHALL JF: Neurotoxic methamphetamine regimen severely impairs recognition memory in rats. Synapse 49: 89-96, 2003.

SCHUTOVÁ B, HRUBÁ L, POMETLOVÁ M, DEYKUN K, ŠLAMBEROVÁ R: Impact of methamphetamine administered prenatally and in adulthood on cognitive functions of male rats tested in Morris water maze. Prague Med Rep 109: 62-70, 2008.

SCHUTOVÁ B, HRUBÁ L, POMETLOVÁ M, DEYKUN K, ŠLAMBEROVÁ R: Cognitive functions and drug sensitivity in adult male rats prenatally exposed to methamphetamine. Physiol Res 58: 741-750, 2009.

SCHUTOVÁ B, HRUBÁ L, POMETLOVÁ M, ROKYTA R, ŠLAMBEROVÁ R: Responsiveness to methamphetamine in adulthood is altered by prenatal exposure in rats. Physiol Behav 99: 381-387, 2010.

SQUIRE LR: Memory and the hippocampus: a synthesis from findings with rats, monkeys, and humans. Psychol Rev 99: 195-231, 1992.

ŠLAMBEROVÁ R, POMETLOVÁ M, CHAROUSOVÁ P: Postnatal development of rat pups is altered by prenatal methamphetamine exposure. Prog Neuropsychopharmacol Biol Psychiatry 30: 82-88, 2006.

ŠLAMBEROVÁ R, BERNÁŠKOVÁ K, MATĚJOVSKÁ I, SCHUTOVÁ B: Does prenatal methamphetamine exposure affect seizure susceptibility in adult rats with acute administration of the same drug? Epilepsy Res 78 : 33-39, 2008.

ŠLAMBEROVÁ R, YAMAMOTOVÁ A, SCHUTOVÁ B, HRUBÁ L, POMETLOVÁ M: Impact of prenatal methamphetamine exposure on the sensitivity to the same drug in adult male rats. Prague Med Rep 112: $102-$ $114,2011$.

VORHEES CV, INMAN-WOOD SL, MORFORD LL, BROENING HW, FUKUMURA M, MORAN MS: Adult learning deficits after neonatal exposure to D-methamphetamine: selective effects on spatial navigation and memory. J Neurosci 20: 4732-4739, 2000.

WILLIAMS MT, MORFORD LL, WOOD SL, WALLACE TL, FUKUMURA M, BROENING HW, VORHEES CV: Developmental D-methamphetamine treatment selectively induces spatial navigation impairments in reference memory in the Morris water maze while sparing working memory. Synapse 48: 138-148, 2003.

WILSON JM, KALASINSKY KS, LEVEY AI, BERGERON C, REIBER G, ANTHONY RM, SCHMUNK GA, SHANNAK K, HAYCOCK JW, KISH SJ: Striatal dopamine nerve terminal markers in human, chronic methamphetamine users. Nat Med 2: 699-703, 1996. 